\title{
Cocktail $\delta$-integration: a novel method to construct cellulolytic enzyme expression ratio-optimized yeast strains
}

\author{
Ryosuke Yamada', Naho Taniguchi', Tsutomu Tanaka22, Chiaki Ogino1', Hideki Fukuda² and Akihiko Kondo*1
}

\begin{abstract}
Background: The filamentous fungus T. reesei effectively degrades cellulose and is known to produce various cellulolytic enzymes such as $\beta$-glucosidase, endoglucanase, and cellobiohydrolase. The expression levels of each cellulase are controlled simultaneously, and their ratios and synergetic effects are important for effective cellulose degradation. However, in recombinant Saccharomyces cerevisiae, it is difficult to simultaneously control many different enzymes. To construct engineered yeast with efficient cellulose degradation, we developed a simple method to optimize cellulase expression levels, named cocktail $\delta$-integration.
\end{abstract}

Results: In cocktail $\delta$-integration, several kinds of cellulase expression cassettes are integrated into yeast chromosomes simultaneously in one step, and strains with high cellulolytic activity (i.e., expressing an optimum ratio of cellulases) are easily obtained. Although the total integrated gene copy numbers of cocktail $\delta$-integrant strain was about half that of a conventional $\delta$-integrant strain, the phosphoric acid swollen cellulose (PASC) degradation activity (64.9 mU/g-wet cell) was higher than that of a conventional strain $(57.6 \mathrm{mU} / \mathrm{g}$-wet cell). This suggests that optimization of the cellulase expression ratio improves PASC degradation activity more so than overexpression.

Conclusions: To our knowledge, this is the first report on the expression of cellulase genes by $\delta$-integration and optimization of various foreign genes by $\delta$-integration in yeast. This method should be very effective and easily applied for other multi-enzymatic systems using recombinant yeast.

\section{Background}

Given the eventual exhaustion of fossil fuels and environmental issues such as global warming and acid rain, utilization of biomass as a source of fuels and fine chemicals has recently become an attractive option. Utilization of biomass, especially cellulosic materials, is desirable because it is abundant, inexpensive, renewable, and has favorable environmental properties. Therefore, an efficient and cost-effective method for degradation of cellulosic materials into glucose to produce alternative fuels or other fine chemicals is required.

Efficient degradation of cellulose requires a synergistic reaction of the cellulolytic enzymes endoglucanase (EG), cellobiohydrolase $(\mathrm{CBH})$, and $\beta$-glucosidase (BGL).

\footnotetext{
* Correspondence: akondo@kobe-u.ac.jp

1 Department of Chemical Science and Engineering, Graduate School of Engineering, Kobe University, 1-1 Rokkodaicho, Nada-ku, Kobe, Hyogo 6578501, Japan

Full list of author information is available at the end of the article
}

Although there are many reports concerning cost reduction for cellulosic material degradation using recombinant bacteria, fungi, and yeast [1-3], cellulase degradation efficiency has not been improved enough. We previously reported direct ethanol production from phosphoric acid swollen cellulose (PASC) using a yeast strain co-displaying Trichoderma reesei EGII, CBHII, and Aspergillus aculeatus BGL1 [4]. This method however requires higher cellulase degradation for cost-effective ethanol production from cellulosic materials.

The filamentous fungus $T$. reesei degrades cellulose effectively and is known to produce various types of cellulolytic enzymes and control their expression levels simultaneously depending on the environment; the ratio of the cellulases and their synergetic effects are important for effective cellulose degradation [5,6]. Promoter engineering is one method to control cellulase expression levels [7-9]. However, the variety of promoters adequate for cellulase overexpression is limited, and expression levels 
by each promoter vary with environmental conditions such as glucose concentration or the phase of cell growth [7]. Furthermore, the optimum expression ratio of various cellulolytic enzymes for efficient cellulose degradation is unknown, and the ratio will differ depending on the content of the cellulosic material.

In this study, to construct engineered yeast with efficient cellulose degradation, we developed a simple method to optimize cellulase expression levels, called cocktail $\delta$-integration. The $\delta$-integration method is known as multicopy-integration in yeast [10]. In cocktail $\delta$-integration, several kinds of cellulase expression cassettes are integrated into yeast chromosomes simultaneously in one step, and strains with high cellulolytic activity (i.e., expressing the optimum ratio of cellulases) can be easily obtained. The goal of this study was to create a cellulase expression-optimized yeast strain for efficient degradation of cellulose using our novel cocktail $\delta$ integration method.

\section{Materials and methods}

Strains, plasmids, and media

Table 1 summarizes the genetic properties of all strains used in this study. In brief, the host for recombinant DNA manipulation was the Escherichia coli strain NovaBlue (Novagen, Madison, WI, USA), and cellulolytic enzymes were expressed in the haploid yeast strain $S$. cerevisiae MT8-1 [11].

E. coli transformants were grown in Luria-Bertani medium (10 g/l tryptone, $5 \mathrm{~g} / \mathrm{l}$ yeast extract, and $5 \mathrm{~g} / \mathrm{l}$ $\mathrm{NaCl})$ supplemented with $100 \mu \mathrm{g} / \mathrm{ml}$ ampicillin. Yeast transformants were screened in SD medium $(6.7 \mathrm{~g} / \mathrm{l}$ yeast nitrogen base without amino acids [Difco Laboratories, Detroit, MI, USA] and $20 \mathrm{~g} / \mathrm{l}$ glucose) supplemented with the appropriate amino acids and nucleic acids. For cocktail $\delta$-integration, SPASC medium $(6.7 \mathrm{~g} / \mathrm{l}$ of yeast nitrogen base without amino acids [Difco Laboratories] and 10 g/l PASC) supplemented with the appropriate amino acids and nucleic acids was used. Yeast cells were aerobi- cally cultured in SD or YPD medium $(10 \mathrm{~g} / \mathrm{l}$ yeast extract, $20 \mathrm{~g} / \mathrm{l}$ Bacto-peptone [Difco Laboratories], and $20 \mathrm{~g} / \mathrm{l} \mathrm{glu-}$ cose).

\section{Plasmid construction}

Table 2 and Figure 1 represent the genetic properties of all plasmids used in this study. The integrative plasmid pIHAGBGL-NotI [12] was used for surface expression of BGL1.

The integrative plasmid for surface expression of T. reesei EGII was constructed as follows: The NotI-NotI DNA fragment encoding the $\mathrm{S}$. cerevisiae PGK1 promoter, a secretion signal sequence, the $\mathrm{T}$. reesei endoglucanase gene, the 3'-half of the $\alpha$-agglutinin gene, and the PGK1 terminator was amplified from pIWAGEGII [12] by PCR with the primers pPGKF(NotI): 5'-ATGCATGCGGCCGCCGATTTGGGCGCGAATCCTT-3' and tAGR (NotI): 5'-ATAAGAATGCGGCCGCTTTGATTATGTTCTTTCTATTTGAATGAGATATG-3'. The fragment was digested with NotI and inserted into the NotI site of the plasmid pRS406 (Stratagene). The resultant plasmid was named pIU-PGAGEG.

The integrative plasmid for surface expression of T. reesei CBHII was constructed as follows: The NotI-NotI DNA fragment encoding the $S$. cerevisiae PGK1 promoter, a secretion signal sequence, the $T$. reesei cellobiohydrolase gene, the $3^{\prime}$-half of the $\alpha$-agglutinin gene, and the PGK1 terminator was amplified from PIHAGCBHII [12] by PCR with the primers pPGKF(NotI) and tAGR(NotI). The fragment was digested with NotI and inserted into the NotI site of the plasmid pRS404 (Stratagene). The resultant plasmid was named pIWPGAGCBH.

The $\delta$-integrative basic plasmid $\mathrm{p} \delta \mathrm{H}$ (HIS3 as a selective marker) was constructed as follows: The XhoI-XhoI DNA fragment encoding the large portion of the promoter-deficient HIS3 (HIS3d) marker gene was amplified from pRS403 (Stratagene) by PCR using the primers HIS3dF (XhoI): 5'-ACCGTCGACCTCGAGCTTCGAA-

Table 1: Characteristics of bacterial and yeast strains used in this study

\begin{tabular}{|c|c|c|}
\hline Strain or plasmid & Relevant features & Reference \\
\hline \multicolumn{3}{|l|}{ Bacterial strain } \\
\hline E. coli Novablue & endA1 hsdR17 $\left(r_{K 12}-m_{K 12}{ }^{+}\right)$supE44 thi-l gyrA96 relA1 lac recA1/F [proAB + lacl q Z $\Delta \mathrm{M} 15:: T n 10\left(\right.$ Tet $\left.\left.^{r}\right)\right]$ & Novagen \\
\hline \multicolumn{3}{|c|}{ S. cerevisiae yeast strains } \\
\hline MT8-1 & ade his3 leu2 trp1 ura3 & {$[11]$} \\
\hline MT8-1/IBEC & ade leu2 Integration of $\beta$-glucosidase, endoglucanase, and cellobiohydrolase gene & this study \\
\hline MT8-1/ठBEC & ade leu $2 \delta$-Integration of $\beta$-glucosidase, endoglucanase, and cellobiohydrolase gene & this study \\
\hline MT8-1/cocסBEC1 & ade his3 leu2 ura3 cocktail $\delta$-Integration of $\beta$-glucosidase, endoglucanase, and cellobiohydrolase gene & this study \\
\hline MT8-1/cocסBEC2 & ade his3 leu2 cocktail $\delta$-Integration of $\beta$-glucosidase, endoglucanase, and cellobiohydrolase gene & this study \\
\hline MT8-1/cocסBEC3 & ade leu 2 cocktail $\delta$-Integration of $\beta$-glucosidase, endoglucanase, and cellobiohydrolase gene & this study \\
\hline
\end{tabular}


Table 2: Characteristics of plasmids used in this study

\begin{tabular}{|c|c|c|c|}
\hline Plasmid & Recombination type & Selection marker & Expressing cellulase gene \\
\hline plHAGBGL-Notl & Integration & HIS3 & $\beta$-Glucosidase \\
\hline pIU-PGAGEG & & URA3 & Endoglucanase \\
\hline pIW-PGAGCBH & & TRP1 & Cellobiohydrolase \\
\hline p $\delta W-P G A G B G L$ & $\delta$-Integration & TRP1 & $\beta$-Glucosidase \\
\hline pסU-PGAGBGL & & URA3 & $\beta$-Glucosidase \\
\hline pסH-PGAGBGL & & HIS3 & $\beta$-Glucosidase \\
\hline p $\delta W-P G A G E G$ & & TRP1 & Endoglucanase \\
\hline pঠU-PGAGEG & & URA3 & Endoglucanase \\
\hline p $\delta H-P G A G E G$ & & HIS3 & Endoglucanase \\
\hline $\mathrm{p} \delta \mathrm{W}-\mathrm{PGAGCBH}$ & & TRP1 & Cellobiohydrolase \\
\hline p $\delta U-P G A G C B H$ & & URA3 & Cellobiohydrolase \\
\hline $\mathrm{p} \delta \mathrm{H}-\mathrm{PGAGCBH}$ & & HIS3 & Cellobiohydrolase \\
\hline
\end{tabular}

GAATATACTAAAA-3' and HIS3dR (XhoI): 5'-GGGCCCCCCCTCGAGTCGAGTTCAAGAGAAAAAAA-3'.

The fragment was inserted into the XhoI site of plasmid $\mathrm{p} \delta$ seq [13] and the resulting plasmid was named $\mathrm{p} \delta \mathrm{H}$.

The $\delta$-integrative plasmid for surface expression of BGL1 was constructed as follows: The NotI-NotI DNA fragment encoding the $S$. cerevisiae PGK1 promoter, a secretion signal sequence, the $A$. aculeatus $\beta$-glucosidase gene, the 3 '-half of the $\alpha$-agglutinin gene, and the PGK1 terminator was obtained by NotI digestion of pIHAGBGL-NotI and inserted into the NotI sites of the plasmids $\mathrm{p} \delta \mathrm{U}, \mathrm{p} \delta \mathrm{W}[13]$, and $\mathrm{p} \delta \mathrm{H}$, respectively. The resultant plasmids were named p $\delta \mathrm{U}-\mathrm{PGAGBGL}, \mathrm{p} \delta \mathrm{W}$-PGAGBGL, and $\mathrm{p} \delta \mathrm{H}-\mathrm{PGAGBGL}$, respectively.

The $\delta$-integrative plasmids for surface expression of EGII were constructed as follows: The NotI-NotI DNA fragment encoding the $S$. cerevisiae PGK1 promoter, the $T$. reesei endoglucanase gene with a secretion signal sequence, and the 3 '-half of the $\alpha$-agglutinin gene with a terminator was obtained by NotI digestion of pIUPGAGEG and inserted into the NotI sites of the plasmids $\mathrm{p} \delta \mathrm{U}, \mathrm{p} \delta \mathrm{W}$, and $\mathrm{p} \delta \mathrm{H}$ to generate $\mathrm{p} \delta \mathrm{U}-\mathrm{PGAGEG}, \mathrm{p} \delta \mathrm{W}-$ PGAGEG, and $\mathrm{p} \delta \mathrm{H}-\mathrm{PGAGEG}$, respectively.

The $\delta$-integrative plasmids for surface expression of CBHII were constructed as follows: The NotI-NotI DNA fragment encoding the $S$. cerevisiae PGK1 promoter, the T. reesei cellobiohydrolase gene with a secretion signal sequence, and the 3 '-half of the $\alpha$-agglutinin gene with a terminator was obtained by NotI digestion of pIWPGAGCBH and inserted into the NotI sites of the plasmids $\mathrm{p} \delta \mathrm{U}, \mathrm{p} \delta \mathrm{W}$, and $\mathrm{p} \delta \mathrm{H}$ to generate $\mathrm{p} \delta \mathrm{U}-\mathrm{PGAGCBH}$, p $\delta W-P G A G C B H$, and $p \delta H-P G A G C B H$, respectively.
(A)

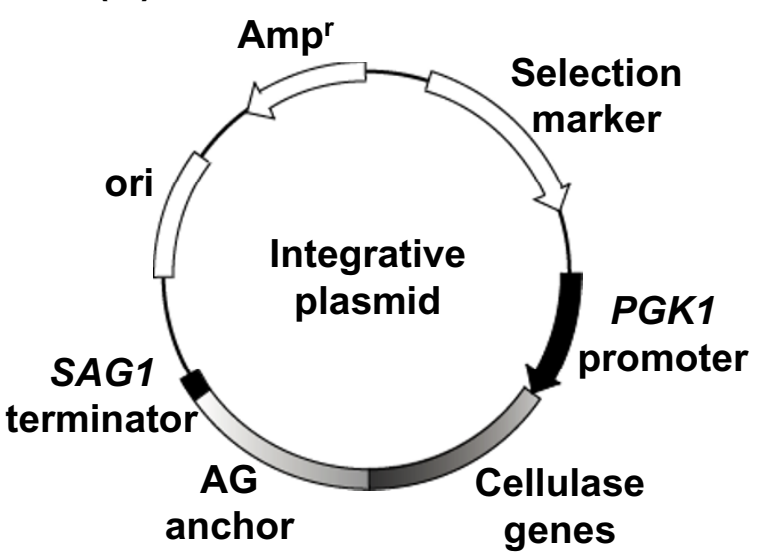

(B)

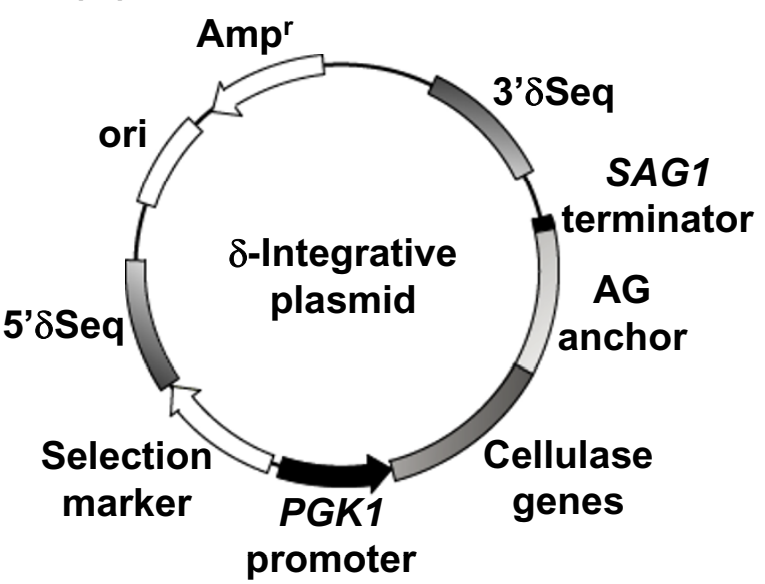

Figure 1 Genetic property of cellulase expressing plasmids. (A) Plasmid for integration. (B) Plasmid for $\delta$-integration. 


\section{Yeast transformation and cocktail $\delta$-integration}

In conventional integration and $\delta$-integration, plasmids were transformed into $S$. cerevisiae MT8-1 using lithium acetate as described [14]. The transformants with the highest cellulolytic activity were selected from several colonies and used in subsequent experiments.

In cocktail $\delta$-integration, identical amounts of three comarked $\delta$-integrative plasmids (over $20 \mu \mathrm{g}$ of each plasmid), p $\delta W-P G A G B G L, p \delta W-P G A G E G$, and $p \delta W-$ PGAGCBH, were mixed and transformed simultaneously. The transformants were spread on SPASC medium, and the transformant with the highest cellulolytic activity was selected from tested over 100 numbers of large colonies. The selected transformant was named MT8-1/coc $\delta$ BEC1 and used in the subsequent transformation, named repeated cocktail $\delta$-integration. Similar to the first step, identical amounts of three comarked $\delta$-integrative plasmids, p $\delta U$-PGAGBGL, p $\delta U$ -

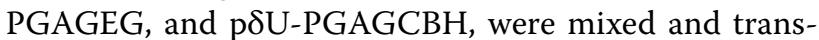
formed into MT8-1/coc $\delta B E C 1$ simultaneously. The selected transformant with the highest cellulolytic activity on SPASC medium was named MT8-1/coc $\delta B E C 2$. Finally, identical amounts of three co-marked $\delta$-integrative plasmids, p $\delta$ H-PGAGBGL, p $\delta$ H-PGAGEG, and p $\delta$ H-PGAGCBH, were mixed and transformed into MT8-1/coc $\delta B E C 2$ simultaneously. The selected transformant with the highest cellulolytic activity on SPASC medium was named MT8-1/coc $\delta$ BEC3.

\section{Enzyme assay}

Yeast cells cultivated in YPD medium for $72 \mathrm{~h}$ at $30^{\circ} \mathrm{C}$ and collected by centrifugation at 3,000 $\times g$ for $5 \mathrm{~min}$ at $4^{\circ} \mathrm{C}$ and washed with distilled water twice were used for determination of $\beta$-glucosidase and PASC degradation activity.

$\beta$-Glucosidase activity was measured in $50 \mathrm{mM}$ sodium acetate buffer ( $\mathrm{pH} 5.0$ ) at $30^{\circ} \mathrm{C}$ with $2 \mathrm{mM}$ p-nitrophenyl$\beta$-D-glucopyranoside (Nacalai Tesque, Inc., Kyoto, Japan) as the substrate. The wet cell concentration of the reaction mixture was adjusted to $1 \mathrm{~g}$-wet cell/l. After the reaction, supernatants were separated by centrifugation at 10 $000 \times g$ at $4^{\circ} \mathrm{C}$. The amount of released p-nitrophenol was determined by measuring the absorbance at $400 \mathrm{~nm}$. One unit of $\beta$-glucosidase activity was defined as the amount of enzyme producing $1 \mu \mathrm{mol} / \mathrm{min}$ p-nitrophenol at $30^{\circ} \mathrm{C}$, $\mathrm{pH}$ 5.0.

PASC degradation activity was determined by hydrolysis of $1 \mathrm{~g} / \mathrm{l}$ amorphous cellulose in $50 \mathrm{mM}$ sodium acetate buffer ( $\mathrm{pH} 5.0)$ at $50^{\circ} \mathrm{C}$. PASC was prepared from Avicel PH-101 (Fluka Chemie GmbH, Buchs, Switzerland) as amorphous cellulose [15]. The wet cell concentration of the reaction mixture was adjusted to $50 \mathrm{~g}$-wet cell/l. After hydrolysis, the supernatant was separated by centrifugation for $5 \mathrm{~min}$ at $10000 \times g$ at $4^{\circ} \mathrm{C}$, and the produced glu- cose concentration was measured using the Glucose CII test Wako (Wako Pure Chemical, Osaka). One unit of PASC degradation activity was defined as the amount of enzyme producing $1 \mu \mathrm{mol} / \mathrm{min}$ glucose at $50^{\circ} \mathrm{C}, \mathrm{pH} 5.0$.

\section{Quantification of integrated copy numbers by real-time PCR}

The integrated copy number of each recombinant strain was quantified using real-time PCR. Template genome DNA was isolated from yeast cells cultivated in SD medium for $72 \mathrm{~h}$ at $30^{\circ} \mathrm{C}$ using a YeaStar Genomic DNA kit (Zymo Research, Orange, CA). The 3 sets of PCR primers, BGL 761F: 5'-CTTCCAGGGCTTTGTGATGTC-3' and BGL 858R: 5'-AGGTGATATCGCCAGGCATT-3', and EGII 694F: 5'-CCACGGTCCAAGAGG TTGTAA-3' and EGII 774R: 5'-GCCAATCATTTCCAGGCAAA-3', and CBHII 571F: 5'-GGCGTCGCCAAA TATAAGAACT-3' and CBHII 653R: 5'-ATAACCAGGAGGGTCCGGATA-3' were used to detect the BGL, EG, and $\mathrm{CBH}$ genes respectively. Quantitative real-time PCR was performed using an ABI PRISM 7000 Sequence Detection System (Applied Biosystems, Foster City, CA) with Thunderbird SYBR qPCR Mix (Toyobo, Osaka, Japan). The normalized gene copy number was calculated by the standard curve method with the PGK1 gene as the house keeping gene.

\section{Results}

\section{General strategy of repeated cocktail $\delta$-integration}

Cocktail $\delta$-integration works as follows. First, three cellulase genes, $\mathrm{BGL}, \mathrm{EG}$, and $\mathrm{CBH}$, were introduced into yeast genomes simultaneously by using the $\delta$-integration method with one marker gene. As a result, a pool of recombinants with various genes having a different number of copies was constructed. Then a transformant with optimized cellulase expression was selected from the recombinant pool by its ability to form colonies on SPASC medium and its cellulolytic activity. Using the selected transformant, a 2 nd round of cocktail $\delta$-integration was carried out using a different marker gene to obtain a transformant with higher PASC degradation ability. After a 3rd round of cocktail $\delta$-integration, the resulting transformant had almost the same PASC degradation activity as the 2 nd round transformant, showing that PASC degradation activity was saturated (see the following section). This strategy is referred to as repeated cocktail $\delta$-integration.

\section{Construction of yeast strains}

The five recombinant yeast strains constructed in this study are shown in Figure 2. The yeast strain MT8-1/ IBEC has BGL, EG, and $\mathrm{CBH}$ genes integrated into its chromosome using a conventional integration method. The $\delta$-integrated strain MT8-1/8BEC and cocktail $\delta$-inte- 


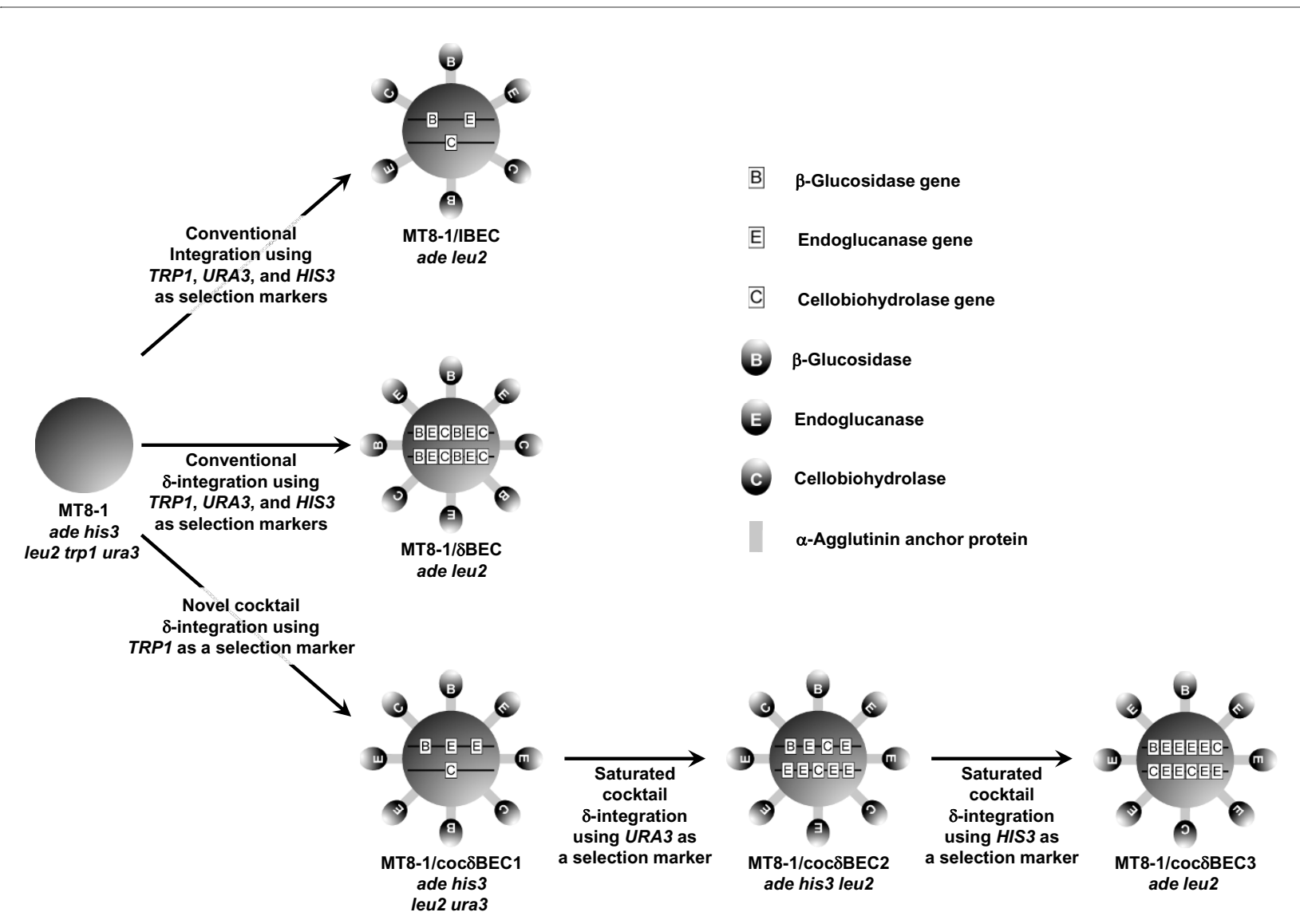

Figure 2 Strategy for constructing cellulase expressing yeast strains.

grated strains $\mathrm{MT} 8-1 / \operatorname{coc} \delta \mathrm{BEC} 1, \mathrm{MT} 8-1 / \operatorname{coc} \delta \mathrm{BEC} 2$, and MT8-1/coc $\delta B E C 3$ have the same genes integrated using the $\delta$-integration and cocktail $\delta$-integration method, respectively.

\section{$\beta$-Glucosidase and PASC degradation activities}

To investigate the effect of cocktail $\delta$-integration, the BGL and PASC degradation activities of each recombinant yeast cell were measured after cultivation on YPD medium. As shown in Figure 3A, the BGL activity of the conventional $\delta$-integrated strain MT8-1/ $\mathrm{BBEC}(14.5 \mathrm{U} / \mathrm{g}$ wet cell) was 3 -fold higher than that of the conventional integrated strain MT8-1/IBEC (4.9 U/g-wet cell). The BGL activities of all cocktail $\delta$-integrated strains (MT8-1/ $\operatorname{coc} \delta \mathrm{BEC} 1, \mathrm{MT} 8-1 / \operatorname{coc} \delta \mathrm{BEC} 2$, and $\mathrm{MT} 8-1 / \operatorname{coc} \delta \mathrm{BEC} 3)$ were lower than that of the conventional integrated strain MT8-1/IBEC.

As shown in Figure 3B, the PASC degradation activity

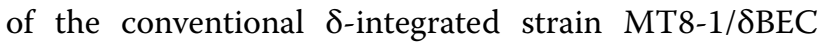
(57.6 mU/g-wet cell) was 5-fold higher than that of the conventional integrated strain MT8-1/IBEC (11.8 U/gwet cell). Alternatively, the PASC degradation activity of the cocktail $\delta$-integrated strain $\mathrm{MT} 8-1 / \operatorname{coc} \delta \mathrm{BEC} 1$ was approximately $64.9 \mathrm{mU} / \mathrm{g}$-wet cell, which was higher than that of MT8-1/8BEC. The PASC degradation activities of repeated cocktail $\delta$-integrated strains $\mathrm{MT} 8-1 / \operatorname{coc} \delta \mathrm{BEC} 2$ and MT8-1/coc $\delta$ BEC3 were respectively 75.8 and 75.1 $\mathrm{mU} / \mathrm{g}$-wet cell, which are almost the same as each other and significantly improved compared to MT8-1/8BEC.

\section{Integrated copy numbers of cellulolytic genes}

To investigate the integrated copy number of transformants, real-time PCR was conducted using each transformant genomic DNA as the template. Figure 4 shows the copy number of cellulase integrated strains. As expected, the number of each integrated gene (BGL, EG, and $\mathrm{CBH}$ ) in the conventional integrated strain MT8-1/IBEC was estimated to be 1 . On the other hand, the number of integrated BGL, EG, and $\mathrm{CBH}$ genes in the conventional $\delta$ integrated strain MT8-1/ $\mathrm{BEC}$ was estimated to be 6,5 , and 9 , respectively. The integrated number of BGL, EG, and $\mathrm{CBH}$ genes in the cocktail $\delta$-integrated strain MT8$1 / \operatorname{coc} \delta B E C 1$ was estimated to be 1,8 , and 2 , respectively, and the EG copy number was increased preferentially after the 2 nd and 3 rd rounds of cocktail $\delta$-integration. 

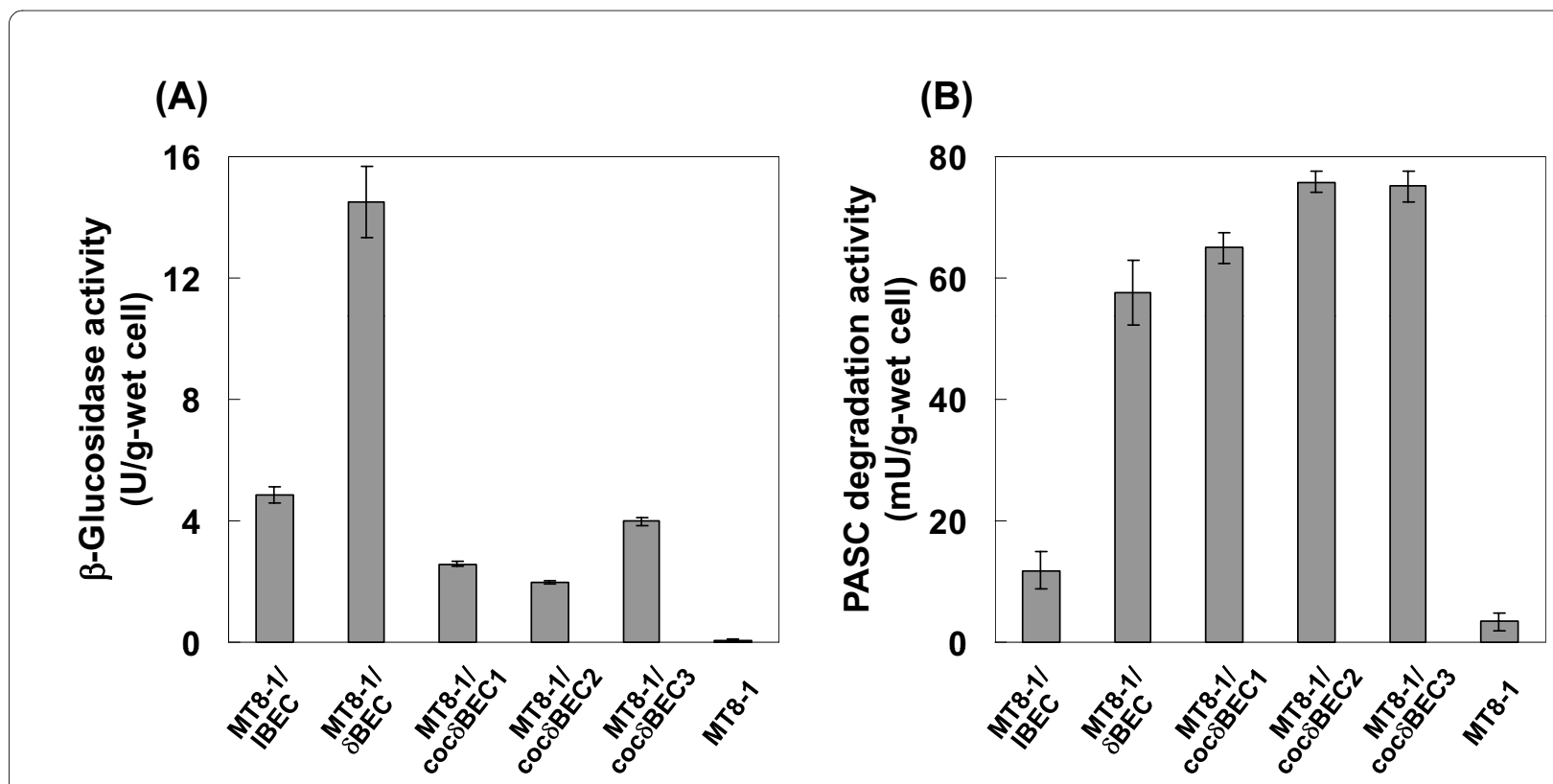

Figure 3 (A) $\beta$-Glucosidase and (B) PASC degradation activities of cellulase expressing yeast strains. MT8-1/IBEC, conventional integrated

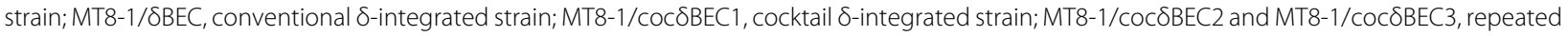
cocktail $\delta$-integrated strain; MT8-1, wild-type strain. Data are averages from five independent experiments.

\section{Discussion}

We developed a high performance cellulolytic yeast strain via a novel $\delta$-integration method by optimizing the expression ratio of three types of cellulase genes. To our knowledge, this is the first report concerning the expression of cellulase genes by $\delta$-integration and optimization of various foreign genes by $\delta$-integration in yeast.

Table 3 shows a summary of results in this study. The BGL activity of the conventional $\delta$-integrated strain

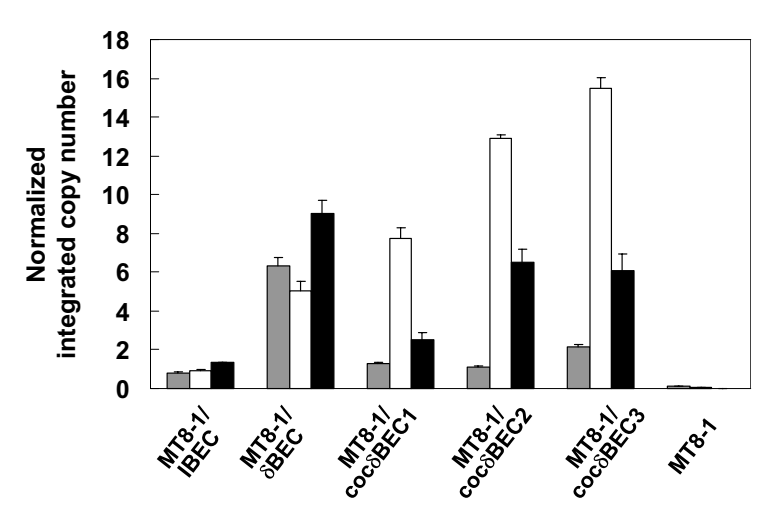

Figure 4 Determination of cellulase gene copy number of cellulase-expressing yeast strains. Gray bar, $\beta$-glucosidase; white bar, endoglucanase; black bar, cellobiohydrolase. MT8-1/IBEC, conventional integrated strain; MT8-1/8BEC, conventional $\delta$-integrated strain; MT81/coc $\delta B E C 1$, cocktail $\delta$-integrated strain; MT8-1/COc $\delta B E C 2$ and MT8-1/ COC $\delta B E C 3$, repeated cocktail $\delta$-integrated strain; MT8-1, wild-type strain. Data are averages from three independent experiments.
MT8-1/ $\mathrm{BEC}$ was the highest among all of the strains constructed in this study. Although all three cocktail $\delta$ integrated strains (MT8-1/coc $\delta \mathrm{BEC} 1, \mathrm{MT} 8-1 / \operatorname{coc} \delta \mathrm{BEC} 2$, and MT8-1/coc $\delta \mathrm{BEC} 3$ ) have lower BGL activity, they show higher PASC degradation activity compared to MT8-1/8BEC. In addition, nearly all the produced soluble sugar from PASC in all strains was glucose, which was confirmed by the Somogyi-Nelson method [16] (data not shown). This clearly shows that BGL activity is sufficient in all strains constructed in this study; however, the EG and $\mathrm{CBH}$ activities are insufficient for efficient PASC degradation. These results correspond to the low copy

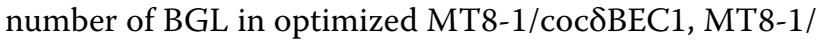
$\operatorname{coc} \delta \mathrm{BEC} 2$, and $\mathrm{MT} 8-1 / \operatorname{coc} \delta \mathrm{BEC} 3$ constructed using repeated cocktail $\delta$-integration (Figure 4 ).

Although the total integrated gene copy number of MT8-1/coc $\delta B E C 1$ was about half that of MT8-1/8BEC, the PASC degradation activity was higher (Table 3). This suggests that optimization of the cellulase expression ratio improves PASC degradation more so than overexpression. Additionally, after the 2nd and 3rd rounds of cocktail $\delta$-integration, the integrated gene copy numbers as well as PASC degradation activity reached a plateau. These results show that uses of repeated cocktail $\delta$-integration can optimize the cellulase expression ratio.

The copy number of integrated EG in the cocktail $\delta$ integrated yeast, MT8-1/coc $\delta \mathrm{BEC} 3$, was the highest compared to that of $\mathrm{CBH}$ or BGL (Table 3). This result indicates the importance of EG expression for efficient 
Table 3: Summary of results

\begin{tabular}{|c|c|c|c|c|c|c|c|}
\hline Strain & $\begin{array}{c}\text { BGLactivity } \\
\text { (U/g-wet } \\
\text { cell) }\end{array}$ & $\begin{array}{c}\text { PASC degradation } \\
\text { activity (mU/g-wet } \\
\text { cell) }\end{array}$ & $\begin{array}{l}\text { Expected } \\
\text { copynumber } \\
\text { of BGL }\end{array}$ & $\begin{array}{c}\text { Expected } \\
\text { copy number } \\
\text { of EG }\end{array}$ & $\begin{array}{l}\text { Expected } \\
\text { copy number } \\
\text { of CBH }\end{array}$ & $\begin{array}{c}\text { Toal } \\
\text { integrated } \\
\text { copy number }\end{array}$ & $\begin{array}{c}\text { Recombination } \\
\text { number }\end{array}$ \\
\hline MT8-1/IBEC & 5 & 12 & 1 & 1 & 1 & 3 & 3 \\
\hline MT8-1/ठBEC & 15 & 58 & 6 & 5 & 9 & 20 & 3 \\
\hline MT8-1/cocठBEC1 & 3 & 65 & 1 & 8 & 2 & 11 & 1 \\
\hline MT8-1/coc $\delta B E C 2$ & 2 & 76 & 1 & 13 & 6 & 20 & 2 \\
\hline MT8-1/cocठBEC3 & 4 & 75 & 2 & 16 & 6 & 24 & 3 \\
\hline MT8-1 & 0 & 3 & 0 & 0 & 0 & 0 & 0 \\
\hline
\end{tabular}

PASC degradation. Many reports have suggested that amorphous cellulose such as PASC and $\beta$-glucan can be degraded into glucose by EG and BGL activity without $\mathrm{CBH}[15,17]$. $\mathrm{CBH}$ activity is more important than EG activity for efficient degradation of crystalline cellulose such as Avicel, and EG activity is more important in the degradation of amorphous cellulose such as PASC [18]. The fact that the integrated EG copy number was increased preferably for PASC degradation is consistent with these previous reports $[15,17,18]$.

One advantage of our cocktail $\delta$-integration method is that optimization of cellulase expression levels for efficient cellulose degradation can be achieved without knowing the optimum cellulase expression ratio. Although the filamentous fungus $T$. reesei, which effectively degrades cellulose, simultaneously controls the expression levels of various cellulolytic enzymes [19], the expression levels and activities of various individual enzymes are still unknown. In addition, the optimum expression ratio varies depending on the cellulosic material and degradation conditions. For the novel cocktail $\delta$ integration method developed in this study, in which we only prepare $\delta$-integrative vectors for a target substrate such as PASC, we can construct a target protein expressing strain with an optimum ratio under the desired conditions. Additionally, using this cocktail $\delta$-integration method, several genes are introduced simultaneously with only a single recombination operation, and the strain with the highest activity can be improved by repeated cocktail $\delta$-integration. This simple procedure not only reduces time and effort, but also facilitates the construction of recombinant industrial yeast strains because of their weak recombinant host character such as lacking of auxotrophic marker [20].

The conventional integration method is not adequate for the optimization of expression because of the low integrated copy number and expression level (Figures 3 and 4 ). Although conventional $\delta$-integration or $2 \mu$-based multicopy plasmid type recombination allow for overex- pression of target genes, it is difficult to control and optimize the expression levels of each gene with these methods. Our cocktail $\delta$-integration method has advantage in that it optimizes the ratio of cellulase expression levels with high cellulolytic activity.

\section{Conclusions}

We constructed three strains of cellulase gene expression-optimized yeast via a novel cocktail $\delta$-integration method. This method should be very effective and easily applied to other multi-enzymatic systems like the degradation of hemicellulose [21]. In addition, it can also be easily applied to the construction of recombinant strains using industrial yeast because several genes are integrated simultaneously in one step.

\section{Abbreviations}

BGL: $\beta$-glucosidase; EG: endoglucanase; $C B H$ : cellobiohydrolase; PASC: Phosphoric acid swollen cellulose; PCR: polymerase chain reaction

\section{Competing interests}

The authors declare that they have no competing interests.

\section{Authors' contributions}

R.Y. designed and performed the experiments. N.T. performed the experiments. R.Y. and T.T. wrote the paper. C.O., H.F., A.K. commented and supervised on the manuscript. All the authors approved the final manuscript.

\section{Acknowledgements}

This work was supported in part by a Grant-in-Aid for JSPS Fellows (21003588), and by the Japanese Ministry of the Environment for Technical Development of Measures to Prevent Global Warming (2007); by the Development of Preparatory Basic Bioenergy Technologies of the New Energy and Industrial Technology Development Organization (NEDO), Tokyo; and Special Coordination Funds for Promoting Science and Technology, Creation of Innovation Centers for Advanced Interdisciplinary Research Areas (Innovative Bioproduction Kobe), MEXT, Japan.

\section{Author Details}

'Department of Chemical Science and Engineering, Graduate School of Engineering, Kobe University, 1-1 Rokkodaicho, Nada-ku, Kobe, Hyogo 6578501, Japan and ${ }^{2}$ Organization of Advanced Science and Technology, Kobe University, 1-1 Rokkodaicho, Nada-ku, Kobe, Hyogo 657-8501, Japan

Received: 11 March 2010 Accepted: 14 May 2010

Published: 14 May 2010 


\section{References}

1. Bayer EA, Belaich JP, Shoham Y, Lamed R: The cellulosomes: multienzyme machines for degradation of plant cell wall polysaccharides. Annu Rev Microbiol 2004, 58:521-554

2. Ito J, Fujita Y, Ueda M, Fukuda H, Kondo A: Improvement of cellulosedegrading ability of a yeast strain displaying Trichoderma reesei endoglucanase II by recombination of cellulose-binding domains. Biotechnol Prog 2004, 20:688-691.

3. Kumar R, Singh S, Singh OV: Bioconversion of lignocellulosic biomass: biochemical and molecular perspectives. J Ind Microbiol Biotechnol 2008, 35:377-391.

4. Fujita Y, Ito J, Ueda M, Fukuda H, Kondo A: Synergistic saccharification, and direct fermentation to ethanol, of amorphous cellulose by use of an engineered yeast strain codisplaying three types of cellulolytic enzyme. Appl Environ Microbiol 2004, 70:1207-1212.

5. Dashtban M, Schraft $H$, Qin W: Fungal bioconversion of lignocellulosic residues; opportunities \& perspectives. Int J Biol Sci 2009, 5:578-595.

6. Stricker AR, Mach RL, de Graaff LH: Regulation of transcription of cellulases- and hemicellulases-encoding genes in Aspergillus niger and Hypocrea jecorina (Trichoderma reesei). Appl Microbiol Biotechnol 2008, 78:211-220

7. Maya D, Quintero MJ, de la Cruz Muñoz-Centeno M, Chávez S: Systems for applied gene control in Saccharomyces cerevisiae. Biotechnol Lett 2008, 30:979-987.

8. Nacken V, Achstetter T, Degryse E: Probing the limits of expression levels by varying promoter strength and plasmid copy number in Saccharomyces cerevisiae. Gene 1996, 175:253-260.

9. Walfridsson M, Anderlund M, Bao X, Hahn-Hägerdal B: Expression of different levels of enzymes from the Pichia stipitis XYL1 and XYL2 genes in Saccharomyces cerevisiae and its effects on product formation during xylose utilization. App/ Microbiol Biotechnol 1997, 48:218-224.

10. Sakai A, Shimizu Y, Hishinuma F: Integration of heterologous genes into the chromosome of Saccharomyces cerevisiae using a delta sequence of yeast retrotransposon Ty. App/ Microbiol Biotechnol 1990, 33:302-306.

11. Tajima M, Nogi Y, Fukasawa T: Primary structure of the Saccharomyces cerevisiae GAL7 gene. Yeast 1985, 1:67-77.

12. Yanase S, Yamada R, Kaneko S, Noda H, Hasunuma T, Tanaka T, Ogino C, Fukuda $\mathrm{H}$, Kondo A: Ethanol production from cellulosic materials using cellulase expressing yeast. Biotechnol $J 2009$ in press.

13. Yamada R, Tanaka T, Ogino C, Fukuda H, Kondo A: Novel strategy for yeast construction using delta-integration and cell fusion to efficiently produce ethanol from raw starch. App/ Microbiol Biotechnol 2009, 85:1491-1498.

14. Chen DC, Yang BC, Kuo TT: One-step transformation of yeast in stationary phase. Curr Genet 1992, 21:83-84.

15. Den Haan RS, Rose $H$, Lynd LR, van Zyl WH: Hydrolysis and fermentation of amorphous cellulose by recombinant Saccharomyces cerevisiae. Metab Eng 2007, 9:87-94.

16. Wood TM, Bhat KM: Methods for measuring cellulase activities. Methods Enzymol 1988, 160:87-112.

17. Fujita Y, Takahashi S, Ueda M, Tanaka A, Okada H, Morikawa Y, Kawaguchi T, Arai M, Fukuda H, Kondo A: Direct and efficient production of ethanol from cellulosic material with a yeast strain displaying cellulolytic enzymes. Appl Environ Microbiol 2002, 68:5136-5141

18. Toda H, Takada S, Oda M, Amano Y, Kanda T, Okazaki M, Shimosaka M: Gene cloning of an endoglucanase from the basidiomycete Irpex lacteus and its CDNA expression in Saccharomyces cerevisiae. Biosci Biotechnol Biochem 2005, 69:1262-1269.

19. IImen M, Saloheimo A, Onnela ML, Penttila ME: Regulation of cellulase gene expression in the filamentous fungus Trichoderma reesei. Appl Environ Microbiol 1997, 63:1298-1306.

20. Akada R: Genetically modified industrial yeast ready for application. $J$ Biosci Bioeng 2002, 94:536-544.

21. Katahira S, Fujita Y, Mizuike A, Fukuda H, Kondo A: Construction of a xylan-fermenting yeast strain through codisplay of xylanolytic enzymes on the surface of xylose-utilizing Saccharomyces cerevisiae cells. Appl Environ Microbiol 2004, 70:5407-5414.

doi: 10.1186/1475-2859-9-32

Cite this article as: Yamada et al., Cocktail ?-integration: a novel method to construct cellulolytic enzyme expression ratio-optimized yeast strains Microbial Cell Factories 2010, 9:32

\section{Submit your next manuscript to BioMed Central} and take full advantage of:

- Convenient online submission

- Thorough peer review

- No space constraints or color figure charges

- Immediate publication on acceptance

- Inclusion in PubMed, CAS, Scopus and Google Scholar

- Research which is freely available for redistribution

Submit your manuscript at www.biomedcentral.com/submit
C Biomed Central 